\title{
A play-at-work intervention: What are the benefits?
}

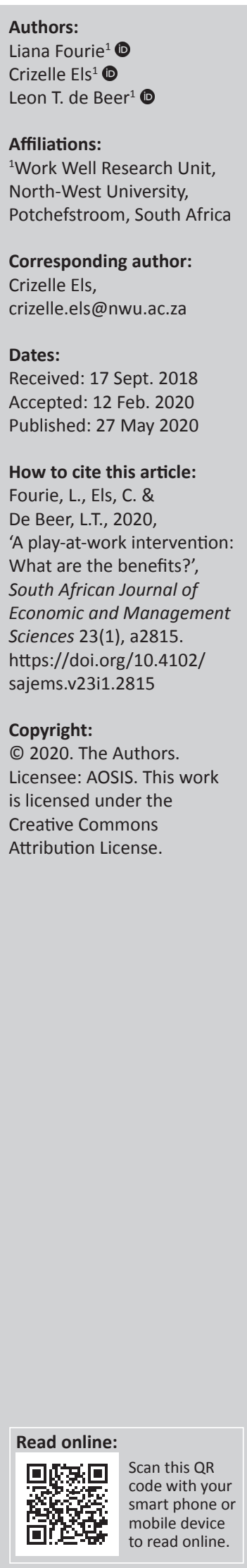

Background: Organisations are investing time and resources in implementing play at work. However, the possible effect of play at work as an organisational intervention is largely unknown.

Aim: This study aimed to determine the effect of a play-at-work intervention on psychological detachment, work enjoyment, employee performance, and workplace boredom of work teams.

Setting: The sample consisted of 26 telemarketing employees in the Northwest Province, South Africa.

Methods: A longitudinal, three-wave intervention study design was followed. The sample consisted of two work teams from a telesales company divided into the experimental group $(n=9)$ and the control group $(n=17)$. A play-atwork intervention consisting of different single-player and multi-player games was developed. Surveys were used to collect data prior to introducing the intervention, after one week of play, and again after the second week of the intervention.

Results: The results indicated that the play-at-work intervention positively influenced employees' psychological detachment during their lunch break. Team performance also increased when the play-at-work intervention was introduced.

Conclusion: Employees who participates in play during their breaks will be more likely to psychologically detach compared to other employees. Also, organisations who implement play will have higher team performance compared to others.

Keywords: play-at-work intervention; psychological detachment; work enjoyment; team performance; workplace boredom.

\section{Introduction}

Traditionally, play and work were seen as opposites, but in the modern workplace, play seems to be intertwined with work (Butler et al. 2011; West 2015). Many organisations have reformed to a fun and playful work environment. West (2015) describes play as a behavioural approach that is characterised by play being voluntary, fun, frivolous, imaginative, and bound by structure or rules in some way. A playful work environment does not directly meet any organisational outcomes, but it can be a pleasurable mood booster as joy is emotionally contagious, resulting in employees learning from one other, improved team cohesion, social relationships, creativity, trust, commitment and productivity (Han, Kim \& Jeong 2016; Sukovic, Litting \& England 2011; Tews, Michel \& Noe 2017; Verenikina \& Hasan 2010; West 2015). Literature has indicated that younger employees may welcome play at work, while the majority of the senior workforce may not enjoy it (Belkin 2007). Research has also proved that fun working environments are more customary in less formal organisations (Bolton \& Plester 2009).

Although the benefits of a playful work environment are confirmed in the literature above, the majority of studies found in the literature study the gamification of work, rather than playing at work. Gamification refers to the application of characteristics from games into non-gaming contexts (Perryer et al. 2016); in other words, gamification suggests that you modify the employees' work into the form of a game. Although this type of work design has proven to have a positive impact on the workplace (Kapp 2012; Perryer et al. 2016), others have revealed that employees do not enjoy being forced by management to play as fun and laughter are spontaneous and not a package with the promise of results (Bolton \& Houlihan 2009). Similarly, West (2015) suggests that play should be done just for fun and for no other reason. Play at work, rather than the gamification

Note This article is partially based on the first author's mini-dissertation submitted in partial fulfilment of the requirements for the Note This article is partially based on the first author's mini-dissertation submitted in partial fulfilment of the requirements for the
degree Master's of Commerce in Industrial Psychology at North-West University, South Africa, with supervisor Dr C.E. and co-supervisor, degree Master's of Commerce in Industrial Psychology at North-West University, South Africa, with supervisor Dr C.E. and co-supervisor,
Prof. L.T.d.B., received May 2018, available from: https://repository.nwu.ac.za/bitstream/handle/10394/30974/Fourie_L.pdf?is Allowed $=\mathrm{y} \&$ sequence $=1$ 
of work, refers to employees playing games just for fun, to enable them to psychologically detach from work and replenish their resources (Hülsheger 2016), before they commence working again. Therefore, for the purpose of this study, play at work was used as a term to describe fun activities or games in the workplace separate from work. Research has shown that playing while at work creates a break in the workday, which may benefit employees' motivation, involvement, relationships and physical and mental fitness (Sørensen \& Spoelstra 2012).

Despite fascinating findings regarding play, empirical research regarding the relationship between play and work is scarce, and consequently the effects of play on organisational outcomes are still relatively unknown (Perryer et al. 2016; Sørensen \& Spoelstra 2012). Therefore, it is against this background that the current study aims to investigate the effect of play as organisational intervention on different workplace constructs.

\section{Review of literature}

\section{Play at work and psychological detachment}

One of the main recovery experiences is psychological detachment which refers to employees refraining from workrelated thoughts and activities during non-work time, thereby disengaging psychologically from work (Sonnentag \& Fritz 2015). It forms part of the conservation of resources (COR) theory and the effort-recovery (E-R) model that emphasise that employees need to recover to restore lost resources (Hülsheger 2016; Sonnentag \& Fritz 2007). Previous studies have been in agreement that it is important for employees' well-being to psychologically detach from work during non-work time as it helps employees to restore energetic and affective resources (Sonnentag \& Fritz 2015; Sonnentag \& Kühnel 2016; Zijlstra, Cropley \& Rydstedt 2014).

Play promotes openness and humour, and helps employees to temporarily relax and forget about objectives (West 2015). A study conducted by Oerlemans, Bakker and Demerouti (2014) revealed that happiness during physical and social activities enhances recovery among employees. Similarly, Trougakos and Hideg (2009) affirm that enjoyable activities help employees to restore their affective resources. However, previous research shows that employees who experience workplace fun had lower levels of emotional exhaustion and emotional conflict (Karl, Peluchette \& Harland 2007). Additionally, employees psychologically detach more when they are fully engaged or absorbed by the off-job activities (Feuerhahn, Sonnentag \& Woll 2014; Hahn, Binnewies \& Haun 2012). Therefore, the assumption could be made that play at work may help employees to psychologically detach from work as it can be an enjoyable activity that is not completely undemanding. Against this background this hypothesis is formulated:

H1: A play-at-work intervention will be effective in increasing the psychological detachment of an experimental group, compared to the psychological detachment of a control group.
Psychological detachment was at first only measured away from work, but Sonnentag and Fritz (2015) argue that employees can psychologically detach from work during their breaks; however, research regarding this is lacking. Therefore, there is a gap in the literature regarding psychological detachment during break times at work, which this study aimed to investigate. Furthermore, another study also identified that employees felt most fatigued before their lunch break than any other part of the day (Hülsheger 2016).

\section{Play at work and work enjoyment}

The workforce of today has changed from the previous years: employees now expect their work to be fun and enjoyable (Romero \& Pescosolido 2008; West 2015). Research has proved that the workplace can have a large impact on employees' happiness and well-being (Rodríguez-Muñoz \& Sanz-Vergel 2013) thereby highlighting the importance to investigate employee's work enjoyment. Work enjoyment refers to the extent that employees perceive their work as pleasurable or enjoyable (Graves et al. 2012).

Peters et al. (2014) explain that work enjoyment is how employees evaluate the quality of their lives at work. The antecedents of work enjoyment include employee characteristics, the employees' work itself and the work environment (Bakker 2008), and therefore this study argues that a play-at-work intervention will influence the work environment, thereby influencing work enjoyment levels:

H2: A play-at-work intervention will be effective in increasing the work enjoyment of an experimental group, compared to the work enjoyment of a control group.

For employees to be happy at work, they need to experience more pleasure (Bakker \& Daniels 2013; Xanthopoulou, Bakker \& Ilies 2012). Positive events such as the play-at-work intervention can lead to employees experiencing positive emotions (Trougakos \& Hideg 2009). According to the broaden-and-build theory, when employees experience positive emotions, it can increase a variety of personal resources (Fredrickson et al. 2008). Consequently, a study by Demerouti et al. (2012) identified that work enjoyment results in lower exhaustion levels and higher vigour levels.

The authors also identified that employees who psychologically detach during off time and who had high levels of work enjoyment also showed higher levels of vigour. Therefore, it is no surprise that research has proved that happy employees can lead to an organisation's competitive advantage (KasperBrauer \& Leischnig 2016). This is supported by other studies that proved that work enjoyment can lead to improved work performance (Engeser \& Rheinberg 2008; Graves et al. 2012; Hsiao et al. 2015).

\section{Play at work and performance}

If an organisation wants to have the competitive edge, it need to ensure that it employs the best persons for the job; however, it seems that the new career enterers value fun at 
work. Thus it is understandable that many organisations are creating a fun work environment since it has an influence on not only the well-being of their employees, but also the reputation of the company, as well as employee performance (Karl et al. 2007). Performance is important for any organisation as it directly influences the profitability of an organisation (Maiga, Nilsson \& Ax 2015). Performance is defined as 'those actions and behaviours that are under the control of the individual and contribute to the goals of the organisation' (Rotundo \& Sackett 2002:66).

Tews, Michel and Stafford (2013) argue that fun at work may allow employees to take a break from work, resulting in employees being more engaged when they start working again, thereby improving performance. Karl et al. (2007) identified that fun at work can increase employee satisfaction and performance. Similarly, Fluegge-Woolf (2014) found that fun at work is directly and positively related to citizenship behaviour and indirectly and positively related to employee performance. Butler et al. (2011) add that the less the office is perceived as dull and dreary, the more value will be added to the bottom line. Therefore, the assumption could be made that the play-at-work intervention will increase employee performance:

H3: A play-at-work intervention will be effective in increasing the team performance of an experimental group, compared to the team performance of a control group.

\section{Play at work and workplace boredom}

Workplace boredom refers to the experience of boredom within the domain of work (Van Wyk et al. 2016). Workplace boredom is described by Schaufeli and Salanova (2014) as 'an unpleasant state of relatively low arousal and dissatisfaction, which is attributed to an inadequately stimulating work situation' (p. 298). When an employee's ability exceeds task complexity, workplace boredom is more likely to be experienced (Schaufeli \& Salanova 2014; Van Wyk et al. 2016). Cummings, Gao and Thornburg (2016) also mentioned that workplace boredom is experienced when employees feel their work is too simple and easy or when they have too little to do. Therefore, workplace boredom has also been linked to employees doing short repetitive work (Schaufeli \& Salanova 2014). Consequently, it is clear that the work environment and job characteristics are seen as main sources of workplace boredom (Loukidou, Loan-Clarke \& Daniels 2009).

According to the mood management theory, employees seek entertainment when they experience workplace boredom (Perryer et al. 2016). The authors further explain that, according to the mood management theory, play at work can satisfy hedonic needs of employees and assist in regulating arousal by reducing the experience of boredom. Jackson and Carter (2011) also argue that employees use boredom to generate the need to do something pleasurable, for instance play at work. Butler et al. (2011) explain that work has an intrinsic relation to the experience of workplace boredom and play represents the employees' desire to escape from it. Therefore, according to the authors, it is understandable that employees implement play in the workplace to cover up the boredom experienced by employees:

H4: A play-at-work intervention will be effective in reducing the workplace boredom of an experimental group, compared to the workplace boredom of a control group.

Although theory suggests that play can reduce workplace boredom, more research is needed to identify the direct influence of play on workplace boredom (Spraggon \& Bodolica 2014).

\section{Method \\ Research design}

A longitudinal, three-wave, pre-test-post-test randomised experimental design was followed. In longitudinal studies, researchers collect data from the same subjects at more than one point in time. A pre-test was administered to the experimental and the control group before a play-at-work intervention was introduced. One post-test was done after one week of implementing the intervention and again after the second week of implementing the intervention. Paperbased questionnaires were used to collect the data.

\section{Research participants}

The sample consisted of employees working at a telesales company in the North West province of South Africa. A nonprobability purposive sampling strategy was followed. The telesales environment may tend to be repetitive, creating an ideal environment for evaluating the intervention developed in this study. The telesales department of the organisation consisted mainly of two work teams and these two teams were randomly assigned to the experimental and the control group. Therefore, both of the teams had an equal chance of being the experimental or the control group (Boot et al. 2013; Reid 2013).

The biographical characteristics of the participants are presented in Table 1.

The sample consisted of two very small groups of employees; all the employees in the department were invited to participate in the study and 26 participants $(N=26)$ completed all three waves of data. The experimental group consisted of 9 participants $(n=9)$ and the control group consisted of 17 participants $(n=17)$. The majority of the experimental group sample were female $(n=6 ; 66.67 \%)$ and $88.89 \%(n=8)$ of the participants were between the ages of 20 and 29 . The control group consisted mostly of men $(n=11 ; 64.71 \%)$ and $88.24 \%$ $(n=15)$ of the sample were between the ages of 20 and 29.

TABLE 1: Biographical characteristics of participants.

\begin{tabular}{llccccc}
\hline Variable & Category & \multicolumn{2}{c}{ Experimental group } & & \multicolumn{2}{c}{ Control group } \\
\cline { 3 - 4 } \cline { 6 - 7 } & & Frequency & $\mathbf{\%}$ & & Frequency & $\%$ \\
\hline \multirow{2}{*}{ Gender } & Female & 6 & 66.67 & & 6 & 35.29 \\
& Male & 3 & 33.33 & & 11 & 64.71 \\
\multirow{2}{*}{ Age } & $20-29$ & 8 & 88.89 & & 15 & 88.24 \\
& $30-39$ & 0 & 0.00 & & 1 & 5.88 \\
& $40-49$ & 1 & 11.11 & & 1 & 5.88 \\
\hline
\end{tabular}




\section{Measuring instruments}

\section{Psychological detachment}

Psychological detachment was measured by adapting the psychological detachment dimension of the Recovery Experience Questionnaire (REQ) of Sonnentag and Fritz (2007). The four psychological detachment items were adjusted to measure psychological detachment during the employees' lunch break when they participated in the playat-work intervention (e.g. 'During my break time I do not think about work at all').

\section{Work enjoyment}

Work enjoyment was measured with the work pleasure scale, a section of the Dutch Questionnaire on the Experiences and Evaluation of Work (Van Veldhoven et al. 1997). This scale has nine items (e.g. 'I enjoy my work') and has been proven to be reliable with a Cronbach's alpha coefficient of 0.80 (Kompier, Taris \& Van Veldhoven 2012).

\section{Team performance}

Team performance was measured with objective performance data provided by the participating organisation. The team performance was calculated with the added total of all team members' number of sales and number of upgrades. The team performance during the two weeks of the intervention (first two weeks of July 2017) was compared to: (1) the team performance in the month preceding the intervention (i.e. first two weeks of June 2017) and (2) team performance by the teams at the same time during the previous year (i.e. first two weeks of July 2016). The experimental group's team performance was also compared to that of the control group.

\section{Workplace boredom}

Workplace boredom was measured with the one-dimensional Dutch Boredom Scale (DUBS) developed by Reijseger et al. (2013). This scale has six items (e.g. 'I tend to do other things during my work') and has reported a Cronbach's alpha coefficient of 0.78 within the South African context (Van Wyk et al. 2016).

All the items were measured on a six-point Likert scale: 1 (Strongly disagree), 2 (Disagree), 3 (Slightly disagree), 4 (Slightly agree), 5 (Agree), 6 (Strongly agree).

Feedback on the experiences and choices of games for the intervention was also included in the survey. Specifically, the open-ended questions that were asked included: 'Please indicate the dates on which you have played this week. Also indicate the length of time you played each day', 'Please indicate which games you have played in this week. Also indicate the approximate time spent on each game', and 'What was your overall experience of this opportunity to play during your lunch break?'

\section{Play-at-work intervention}

For the purpose of this study a play-at-work intervention was developed. As employees might not share the same interest in games, the intervention consisted of different single-player and multi-player games and the games catered for individuals who enjoy sport-like, creative, thinking, board-based and puzzle games. Employees were free to choose which games they wanted to play during the intervention (Perryer et al. 2016). The 13 games that were implemented were chosen after consulting with experts in the field of industrial psychology. Table 2 provides a brief description of the games that were included in the intervention.

\section{Research procedure}

The first survey (pre-test) was administered to both the experimental and the control group prior to introducing the intervention. During the first week of introducing the intervention, only the experimental group had the opportunity to play during their lunch break for one hour.

TABLE 2: Intervention games.

\begin{tabular}{|c|c|}
\hline Game & Description \\
\hline Foosball & $\begin{array}{l}\text { This is a table game that resembles soccer in which a ball is moved by turning rods to which small figures of players are attached. This game is typically } \\
\text { played by more than one player. }\end{array}$ \\
\hline Darts & $\begin{array}{l}\text { Darts is a throwing sport in which individuals throw small missiles at a targeted dartboard. Points are earned according to allocated spots on the dart } \\
\text { board. This game can be played by one or more players. }\end{array}$ \\
\hline Adult colouring & Adult colouring refers to line art to which people need to add colour with crayons, coloured pencils or marker pens. \\
\hline Neon-paint doodling & This refers to painting images with paint that glows when exposed to fluorescent light. \\
\hline 30 Seconds & $\begin{array}{l}30 \text { Seconds is a fast-paced game that is based on an individual's general knowledge. One player must guess as many words correct in } 30 \text { seconds from } \\
\text { their teammate's explanation. Two or more individuals can play this game. }\end{array}$ \\
\hline Heads Up & $\begin{array}{l}\text { An electronic device (phone or tablet) is held against the forehead of one player, containing a word. The player should guess the word by following the } \\
\text { clues given by team members. It can be played with two or more players. }\end{array}$ \\
\hline Scrabble & This is a board game that is based on forming words and earning points accordingly. This can be played with two to four players. \\
\hline Fingerboard & $\begin{array}{l}\text { This game is played on a square wooden board and the goal is to shoot disks into side pockets of the board, using your fingers. One to four players can } \\
\text { play this game. }\end{array}$ \\
\hline Jenga & $\begin{array}{l}\text { This game is represented by a stack of wooden blocks. Two or more players take turns to remove a wooden block and replace it on top of the stack with } \\
\text { one hand, until the tower falls. }\end{array}$ \\
\hline Crossword puzzles & $\begin{array}{l}\text { A crossword is a word puzzle consisting of a grid of squares, usually containing clues. The goal is to correctly guess the words or phrases to complete } \\
\text { the grid. }\end{array}$ \\
\hline Playing cards & Normal cards (Bicycle cards) that are used in games such as snap and poker. \\
\hline Dominoes & $\begin{array}{l}\text { There are many games that can be played with dominoes, but the simplest and most played is known as 'block dominoes'. Two to four players take turns } \\
\text { to place one of their dominoes onto the table, so all dominoes are linked based on the number of dots on each domino. }\end{array}$ \\
\hline
\end{tabular}


After the first week of introducing the play-at-work intervention, both the experimental and the control groups completed the first post-test. To also allow the control group to have the opportunity to play, both the experimental and control group had the opportunity to play during the second week of the intervention. After the second week of play, both the experimental and the control group completed the second post-test. Figure 1 illustrates the implementation of the playat-work intervention and the research procedure followed to collect the data.

All the questionnaires were distributed by hand and participants anonymously deposited their completed surveys in a sealed box provided. A unique code was generated by each of the participants that consisted of the first three letters of the employee's mother's name, followed by the first three letters of their father's name. The unique code protected the identity of the participants and also assisted in identifying the employees who completed surveys on more than one occasion.

\section{Statistical analysis}

The Statistical Package for the Social Sciences (SPSS) version 24 (IBM Corp. 2017) was used to perform statistical analyses. Descriptive statistics provided a summary of the data: measures of central tendency were calculated with the mean and median scores; measures of dispersion were calculated with variance, standard deviation, range, and skewness and kurtosis scores (Struwig \& Stead 2013). Statistical significance was set at the 0.05 level (i.e. $p<0.05$ ). The independent sample $t$-test was used to test for statistical differences between mean scores of the two groups (Elliott \& Woodward 2007). The SPSS

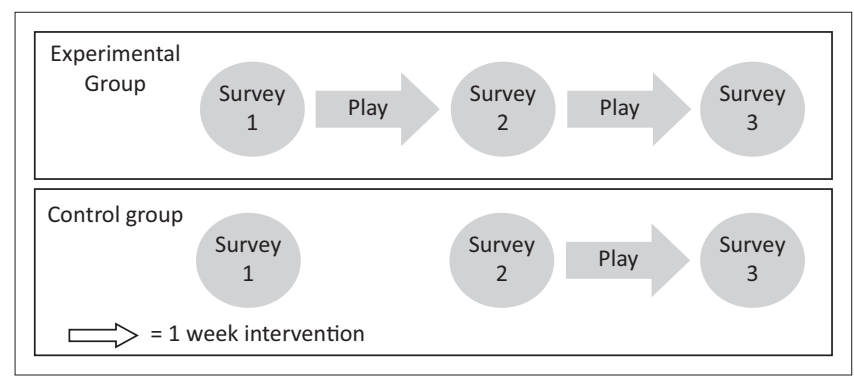

FIGURE 1: Research procedure. program includes Levene's test to investigate for the homogeneity of variances.

The mean scores of psychological detachment, work enjoyment and workplace boredom were compared within and between the groups to ascertain if there were any significant differences between the scores on the variables over time. The three different waves of data from the experimental group were compared (within groups) and the three different waves of data from the control group were also compared (within groups). The mean scores of the experimental group were also compared to the mean scores of the control group (between groups). To determine whether the intervention had the same impact on both groups during their first week of play, the mean scores of the second wave of data of the experimental group were also compared to the mean scores of the third wave of data from the control group.

When the independent sample $t$-test indicated statistically significant differences in mean scores, an effect size was calculated (i.e. Cohen's $d$ value). Cohen's $d$ value represented the standardised mean differences between groups with small effects $(d=0.20)$, medium effects $(d=0.50)$ and large effects $(d=0.80)$ (Ellis 2010).

\section{Ethical consideration}

Ethical clearance has been obtained from the Economic and Management Sciences Research Ethics Committee (EMSREC), North-West University (ethics no. NWU-00439-17-A4) prior to conducting the study.

\section{Results}

The distribution of scores is presented in Table 3.

The data set was normally distributed since the skewness and kurtosis scores were between 1 and -1 , as can be seen in Table 3 (Reid 2013). All the requirements for an independent sample $t$-test were met as Levene's test supported homogeneity of variances. This analysis indicated that all the results had equal variances assumed, as none of Levene's tests for equality of variances' results proved to be statistically significant $(p<0.05)$.

TABLE 3: Data distribution.

\begin{tabular}{|c|c|c|c|c|c|c|c|}
\hline Variable & Mean & Median & Variance & Standard deviation & Range & Skewness & Kurtosis \\
\hline Psychological detachment & 15.37 & 15.50 & 23.22 & 4.82 & 19.00 & -0.03 & -0.70 \\
\hline Work enjoyment & 29.00 & 28.00 & 22.18 & 4.71 & 25.00 & 0.50 & 0.43 \\
\hline Workplace boredom & 16.62 & 15.50 & 41.64 & 6.45 & 25.00 & 0.20 & -0.79 \\
\hline
\end{tabular}

TABLE 4: Group mean scores and standard deviations.

\begin{tabular}{|c|c|c|c|c|c|c|c|c|c|c|c|c|}
\hline \multirow[t]{3}{*}{ Variable } & \multicolumn{6}{|c|}{ Experimental group } & \multicolumn{6}{|c|}{ Control group } \\
\hline & \multicolumn{2}{|c|}{ Survey 1} & \multicolumn{2}{|c|}{ Survey 2} & \multicolumn{2}{|c|}{ Survey 3} & \multicolumn{2}{|c|}{ Survey 1} & \multicolumn{2}{|c|}{ Survey 2} & \multicolumn{2}{|c|}{ Survey 3} \\
\hline & $M$ & S.D. & $M$ & S.D. & $M$ & S.D. & $M$ & S.D. & $M$ & S.D. & $M$ & S.D. \\
\hline Psychological detachment & 10.67 & 3.28 & 17.33 & 2.74 & 18.89 & 2.62 & 12.53 & 3.86 & 13.59 & 4.21 & 19.59 & 3.76 \\
\hline Work enjoyment & 31.11 & 5.09 & 28.89 & 4.08 & 29.89 & 4.08 & 28.82 & 3.89 & 28.94 & 5.32 & 27.71 & 5.38 \\
\hline Workplace boredom & 19.22 & 4.52 & 18.67 & 5.29 & 17.56 & 5.39 & 16.00 & 7.01 & 15.71 & 7.82 & 15.18 & 6.43 \\
\hline
\end{tabular}

M, mean value; S.D., standard deviation. 
When comparing the mean scores, as seen in Table 4, the mean score for psychological detachment is noticeably lower at survey 1 for the experimental group when compared to the other surveys and the control group, with a standard deviation of 3.28. Furthermore, it can be seen that the mean score for psychological detachment of the control group increased considerably from survey 2 to survey 3 after the introduction of play. The results showed that the mean scores for work enjoyment and workplace boredom stayed relatively unchanged across the three surveys.

As seen in Table 5, when comparing the pre-test (survey 1) and the post-test (survey 2) of the experimental group, statistically significant differences were indicated for psychological detachment $(p<0.001)$. Cohen's $d$ value $(d=2.207)$ indicated a large practical effect between these mean scores. There were no statistical differences for work enjoyment and workplace boredom.

The mean scores of the pre-test (survey 1) were compared with the second post-test (survey 3 ) of the experimental group and the results indicate statistically significant differences $(p<0.001)$ for psychological detachment with Cohen's $d$ value indicating a large practical effect size difference $(d=2.771)$. However, no statistical differences were indicated for work enjoyment and workplace boredom. Also, no statistical differences were found when comparing the first (survey 2) and the second post-test (survey 3 ) of the experimental group.

As seen in Table 5 no statistically significant differences were indicated when comparing the pre-test of the experimental group to the pre-test of the control group. When comparing the results of the second survey of the experimental group to those of the control group, statistically significant results were found at psychological detachment $(p=0.025)$, with Cohen's $d$ value indicating a large practical effect $(d=1.054)$. Again, no statistical differences were indicated for work enjoyment and workplace boredom.

TABLE 5: Independent sample t-test results.

\begin{tabular}{lccc}
\hline Variable & $p$ & \multicolumn{3}{c}{ Mean difference } & Cohen's $\boldsymbol{d}$ \\
\hline Independent sample $\boldsymbol{t}$-test survey $\mathbf{1}$ and survey $\mathbf{2}$ of the experimental group \\
Psychological detachment & $0.001^{*}$ & -6.667 & 2.207 \\
Work enjoyment & 0.322 & 2.222 & - \\
Workplace boredom & 0.814 & 0.556 & - \\
Independent sample $\boldsymbol{t}$-test survey $\mathbf{1}$ and survey $\mathbf{3}$ of the experimental group \\
Psychological detachment & $0.001^{*}$ & -8.222 & 2.771 \\
Work enjoyment & 0.581 & 1.222 & - \\
Workplace boredom & 0.487 & 1.667 & - \\
Independent sample $\boldsymbol{t}$-test survey $\mathbf{2}$ of the experimental and the control group \\
Psychological detachment & $0.025^{*}$ & 3.745 & 1.054 \\
Work enjoyment & 0.980 & -0.052 & - \\
Workplace boredom & 0.320 & 2.961 & - \\
Independent sample $\boldsymbol{t}$-test survey $\mathbf{1}$ and survey $\mathbf{3}$ of the control group & \\
Psychological detachment & $0.001^{*}$ & -7.059 & 1.853 \\
Work enjoyment & 0.493 & 1.118 & - \\
Workplace boredom & 0.723 & 0.824 & - \\
\hline
\end{tabular}

*, significant; $d$, effect size.
Finally, Table 5 indicates that no statistically significant differences were indicated when comparing the third survey of the experimental group to that of the control group. When comparing the results of the first week of play of both groups (survey 2 of the experimental group and survey 3 of the control group), no statistically significant differences were indicated. No statistically significant differences were identified when comparing the control group's mean scores of the pre-test (survey 1) to the first post-test (survey 2). There were statistical differences $(p<0.001)$ indicated at psychological detachment when comparing the pre-test (survey 1 ) to the second post-test (survey 3) of the control group, and Cohen's $d$ value indicated a large practical effect $(d=1.853)$. When comparing survey 1 and survey 3 of the control group, again no statistical differences were found for work enjoyment and workplace boredom.

To assess team performance, the number of sales and upgrades made per team were calculated during the intervention (i.e. first two weeks of July 2017), one month prior to the intervention (i.e. first two weeks of June 2016) and one year prior to the intervention (i.e. first two weeks of July 2016). Firstly, the team performance of the experimental group for July 2017 was compared to the same team's performance for July 2016. The results indicate that the team's performance was higher during the intervention in July 2017 when compared to July 2016. When comparing the control group's performance for July 2017 with the previous year, July 2016, the results indicate that the control group also performed better when participating in the intervention.

Furthermore, the results suggest that the experimental group's performance during the intervention was higher than their performance the previous month, June 2017, as seen in Figure 2. The experimental group's team performance

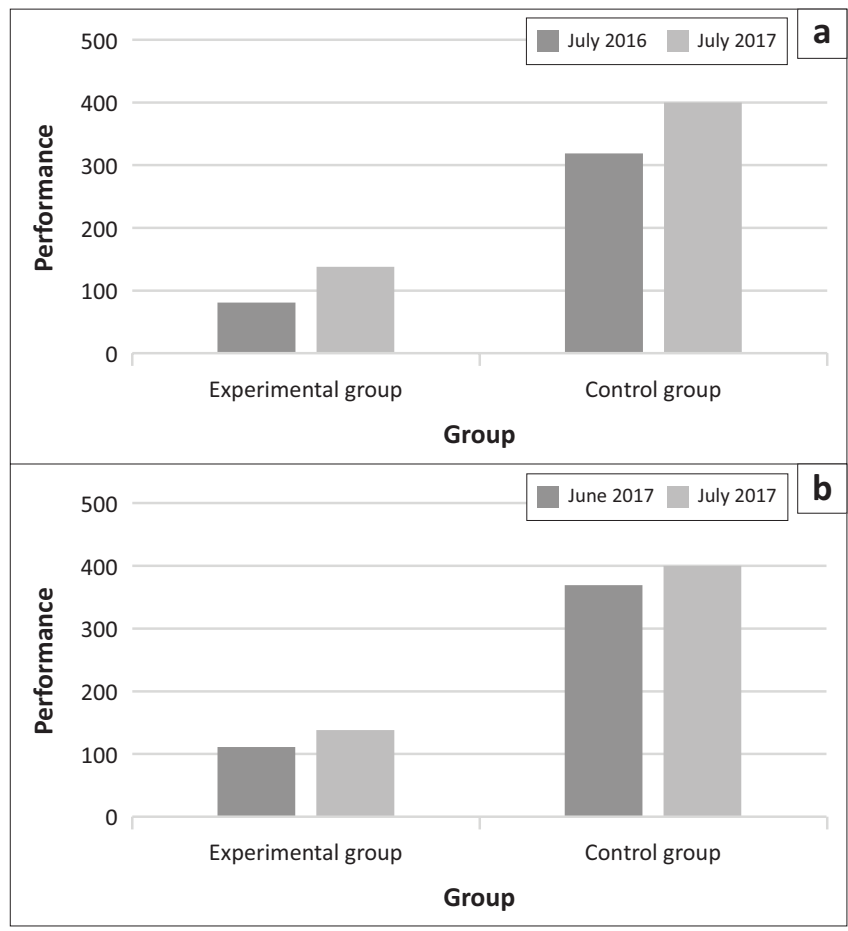

FIGURE 2: Comparison of team performance in the experimental and control groups: (a) July 2016 and July 2017; (b) June 2017 and July 2017. 
TABLE 6: Collective minutes played per team, per week.

\begin{tabular}{|c|c|c|c|c|c|c|}
\hline \multirow[t]{2}{*}{ Variable } & \multicolumn{2}{|c|}{ Experimental group } & \multicolumn{2}{|c|}{ Experimental group } & \multicolumn{2}{|c|}{ Control group } \\
\hline & Number of participants & Total minutes week 1 & Number of participants & Total minutes week 2 & Number of participants & Total minutes week 2 \\
\hline Neon-paint doodling & 4 & 360 & 2 & 105 & 7 & 655 \\
\hline Darts & 7 & 290 & 7 & 370 & 10 & 435 \\
\hline 30 Seconds & 7 & 320 & 5 & 225 & 12 & 405 \\
\hline Foosball & 6 & 160 & 4 & 175 & 8 & 295 \\
\hline Playing cards & 7 & 265 & 5 & 180 & 7 & 260 \\
\hline Adult colouring & 1 & 30 & 0 & 0 & 2 & 75 \\
\hline Heads Up & 1 & 60 & 0 & 0 & 1 & 10 \\
\hline Scrabble & 0 & 0 & 0 & 0 & 5 & 105 \\
\hline Dominoes & 1 & 15 & 0 & 0 & 1 & 15 \\
\hline Jenga & 0 & 0 & 0 & 0 & 2 & 30 \\
\hline Crossword puzzles & 1 & 30 & 0 & 0 & 0 & 0 \\
\hline Sudoku & 0 & 0 & 1 & 15 & 1 & 12 \\
\hline
\end{tabular}

during the first week of the intervention was also compared to their performance during the second week of the intervention. The results revealed that more sales were made during the second week of introducing the intervention than the first week of the intervention. Comparison of the control group's results to that of the month before the intervention was implemented (June 2017) indicated that the control group performed better while participating in the intervention, as seen in Figure 2.

Additional data was also gathered in the second and third survey to document the number of participants interested in each game, the total amount of time spent on each game, as well as the experiences of the employees playing these games. Table 6 illustrates the number of participants who played each of the games per week, and the total time (in minutes) each team spent playing each game per week. Both the experimental and control groups seemed to have enjoyed the foosball, darts, neon-paint doodling, 30 Seconds, fingerboard and playing cards. Less play time was spent on adult colouring, Heads Up, Scrabble, Jenga, crossword puzzles, Sudoku and dominoes.

\section{Discussion}

This study aimed to determine the effect of a play-at-work intervention on organisational outcomes of work teams by specifically investigating psychological detachment, work enjoyment, team performance and workplace boredom. This study sought to address the gap in the literature, as previous research regarding the application of play to the workplace context is sparse and as psychological detachment during employees' lunch break has not been fully investigated (Perryer et al. 2016; Sonnentag \& Fritz 2015; West 2015). To this end, a play-at-work intervention was implemented in a telesales organisation in South Africa for two weeks.

Hypothesis 1 stated that a play-at-work intervention will be effective in increasing the psychological detachment of an experimental group, compared to the psychological detachment of a control group. The results support this hypothesis as the second survey indicated that the experimental group experienced higher levels of psychological detachment during their lunch break when participating in the play-at-work intervention compared to the control group who at this stage did not participate in the intervention. The results of comparing survey 1 and survey 2 of the experimental group also confirmed that employees psychologically detached more while participating in the intervention. This hypothesis was again supported when comparing survey 1 and survey 3 of the experimental group and survey 1 and survey 3 of the control group. These results support the arguments that employees can psychologically detach during their lunch break and that leisure activities that are enjoyable, positive and not completely undemanding help employees to psychologically detach (Sonnentag \& Fritz 2015; Trougakos \& Hideg 2009; Tucker et al. 2008).

These findings suggest that a play-at-work intervention has the potential to allow employees to psychologically detach from their work. This finding is important, as the benefits of psychological detachment for both the individual and the organisation has been noted in previous research, indicating its impact. For example, a study by Moreno-Jiménez et al. (2009) found that psychological detachment moderates the relationship between workplace bullying and psychological strain. Previous research also suggests that psychological detachment from work alleviated the negative relationship between relationship conflicts at work and well-being (Sonnentag, Unger \& Nägel 2013). It was also found that psychological detachment moderated the relationship between role conflict and anxiety (Moreno-Jiménez et al. 2012). Sonnentag, Binnewies and Mojza (2010) identified in a longitudinal study that psychological detachment from work has an impact on emotional exhaustion and buffers the relationship between job demands and psychosomatic complaints. The authors also identified that psychological detachment moderates the relationship between job demands and work engagement.

Hypothesis 2 of this study stated that a play-at-work intervention will be effective in increasing the work enjoyment of an experimental group, compared to the work enjoyment of the control group. This hypothesis was rejected as the results suggested that both the experimental group 
and control group's work enjoyment levels were relatively unaffected by the intervention. A possible reason for the lack of significant increase in work enjoyment may be because the play-at-work intervention took place during the employees' lunch break and therefore did not have anything to do with the employees' work itself. Sanz-Vergel and Muñoz (2013) also explained that work enjoyment refers to employees feeling happy while working. Research regarding the gamification of work may possibly yield more significant results when trying to establish a relationship between play and the work itself, since gamification entails the application of game characteristics into non-gaming contexts (Perryer et al. 2016), meaning that you transform the employees' work into the form of a game.

Hypothesis 3 stated that a play-at-work intervention will be effective in increasing the team performance of an experimental group, compared to the team performance of the control group. The results from this study did indeed indicate that a play-atwork intervention has the potential to increase employee performance. It was found that the performance of the experimental group slightly increased during the duration of the intervention compared to the team's performance one month prior to the intervention, and also during the same time of the previous year. However, the control group's results also indicated that the team performance improved when participating in the play-at-work intervention. Therefore, according to the results, the play-at-work intervention seemed to improve the team performance of the experimental and the control group, thereby supporting hypothesis 3 . These results are in line with Sørensen and Spoelstra (2012) who stated that play in an organisation is productive for work. Verenikina and Hasan (2010) also argued that play at work is an influence on the emotional climate and performance of an organisation. Previous research also indicated that recovery among employees predicts improved performance (Binnewies, Sonnentag \& Mojza 2010; Halbesleben, Wheeler \& Paustian-Underdahl 2013; Volman, Bakker \& Xanthopoulou 2013). This may also explain the increase in the team performance in this study.

Hypothesis 4 suggested that a play-at-work intervention will be effective in reducing the workplace boredom of an experimental group, compared to the workplace boredom of a control group, which was not confirmed by the results. There were no statistically significant differences indicated in workplace boredom when the groups were compared, thereby indicating that the levels of workplace boredom experienced by the employees did not change during the play-at-work intervention. Therefore, the hypothesis is rejected. These results are in contrast to the suggestion made by Butler et al. (2011) that work and play have a relationship with boredom experienced by employees. These results also do not support that games in the workplace can help to restore a deficit such as boredom, as explained by the mood management theory (Perryer et al. 2016). Research has proved that when employees' abilities exceed their task complexity, and when they have too little to do, they are more prone to experiencing workplace boredom (Cummings et al. 2016; Schaufeli \& Salanova 2014; Van Wyk et al. 2016). The lack of decline in workplace boredom experienced in our study may be explained by the fact that the play-at-work intervention may have given employees the opportunity to do something else when they experience workplace boredom, but it did not change the employee's task complexity. Another reason for the rejection of the hypothesis may be due to the short duration of the play-at-work intervention.

The question can be raised whether two weeks of intervention allows sufficient time to recover from boredom at work.

Previous studies identified that employees under the age of 30 are more prone to enjoy fun in the workplace (Belkin 2007; Tews, Michel \& Bartlett 2012). The participants in this study were all almost younger than $30: 88.89 \%$ of the experimental group were younger than 30 , and $88.24 \%$ of the control group were also younger than 30 . For this reason, the age of the majority of the sample could have had an impact on the results. As employees older than 30 are not inclined to participate in fun at work, an older workforce may not have participated in the play-at-work intervention, which could have resulted in no statistically significant findings. The results also suggest that the participants showed interest in different games. This is in line with Perryer et al. (2016) who stated that all employees will not be interested in the same games, as well as with Karl et al. (2007) who identified that fun may be welcomed by some employees and not by others. Both teams seemed to enjoy the neonpaint doodling, foosball, darts, 30 Seconds, fingerboard and playing cards; interestingly, all of these games are group based, except for the neon-paint doodling. Employees showed little to no interest in the individual games, for example adult colouring and crossword puzzles. Furthermore, the participants' positive experiences indicated that the play-at-work intervention was relaxing for the employees and it helped them to forget about work for a moment. Participants also reported that they got to know their colleagues in a new way. Participants reported that they also felt more focused and positive after playing in their lunch breaks.

These findings support Trougakos and Hideg (2009) who identified that the experience of positive events also enhances the experience of positive emotions. This also builds on the broaden-and-build theory that conceives when employees experience positive emotions, it helps them to increase personal resources (Fredrickson et al. 2008).

\section{Practical implications}

In this study, it was found that play at work can increase the psychological detachment of employees.

Psychological detachment can be greatly beneficial for the individual and the organisation. Research has shown that psychological detachment plays a moderating role in the relationships between some important organisational variables, including the relationship between workplace 
relationship conflicts and well-being (Sonnentag et al. 2013); it also moderates the relationship between anxiety and role conflict in organisations (Moreno-Jiménez et al. 2012) and psychological detachment moderates the relation between job demands and work engagement (Sonnentag et al. 2010). Therefore, based on this study's results, it can be recommended that organisations should invest in implementing play at work to help employees to psychologically detach from work as it can benefit an organisation in the long run.

Furthermore, it can be suggested that when organisations invest time and resources to introduce playing at work, it may increase their bottom line, as play at work improves team performance, and performance has been proven to directly influence the profitability of an organisation (Maiga et al. 2015).

Despite the positive consequences playing at work may have on employees and their performance, organisations should remember before implementing play in the workplace that some employees may welcome play in the workplace, while others may not (Karl et al. 2007). For organisations to benefit from playing in the workplace, it is therefore important to match play with the employees. Furthermore, all employees differ and as a result they will not be interested in the same type of games (Perryer et al. 2016), and consequently it is also important to match the type of games with the employees in the organisation. Research has shown that younger employees (Belkin 2007) and more informal organisations (Bolton \& Plester 2009) are more inclined to enjoy fun in the workplace. However, this does not mean that older employees or employees in more formal work settings may not benefit from playing at work. In the case of these employees, the organisation might need to convince the employees of the possible benefits of playing at work in order to win their buy-in. It can also be recommended that these employees are given the opportunity to express their preferences of the types of games they are interested in.

\section{Limitations and recommendations}

This study is not without limitations. Firstly, the duration of this study was only two weeks. Consequently, the long-term effect of the intervention is still unknown. One could have done a final survey one or two months after the intervention to determine whether the inclines in psychological detachment and performance were prolonged effects or only short-term results. Furthermore, it can be argued that two weeks might not have been enough time to influence levels of work enjoyment and workplace boredom. It is therefore suggested that future research should explore the possibility of a prolonged play-at-work intervention and the influence of such a longer duration on employee outcomes.

Secondly, the intervention was implemented in a telesales organisation in the North West province of South Africa. The participating organisation is described by its management as informal. Previous research has indicated that informal types of organisations are more inclined to participate in play at work (Bolton \& Plester 2009), and therefore this type of intervention may not have the same effect in a more formal organisation as employees may not participate in the play-atwork intervention and therefore the intervention may not have the same results. For this reason, these results cannot be generalised to all organisations within the South African context. Furthermore, this sample only had 9 participants in the experimental group and 17 participants in the control group. As estimates in small samples can be incorrect (Schönbrodt \& Perugini 2013), no reliability or correlations could be calculated. It can therefore be suggested that future research should utilise a larger sample to address this limitation.

\section{Acknowledgements Competing interests}

The authors have declared that no competing interests exist.

\section{Authors' contributions}

L.F. fulfilled the role of the primary researcher, and this study formed part of her master's research. She was responsible for the conceptualisation of the article, collecting of the data, the interpretation of the research results, and the writing of the article. C.E. acted as supervisor and L.T.d.B. as co-supervisor to this study, and thus played an advisory role in this study and assisted in the conceptualisation of the study and the writing of the research article. L.T.d.B. also conducted the statistical analyses.

\section{Funding information}

This study was in part funded by the WorkWell Research Unit of the North-West University.

\section{Data availability statement}

Data sharing will be done in line with the ethics approval for this study. Access to data can be requested from the corresponding author.

\section{Disclaimer}

The views and opinions expressed in this article are those of the authors and do not necessarily reflect the official policy or position of any affiliated agency of the authors.

\section{References}

Bakker, A.B., 2008, 'The work-related flow inventory: Construction and initia validation of the WOLF', Journal of Vocational Behavior 72(3), 400-414. https:// doi.org/10.1016/j.jvb.2007.11.007

Bakker, A.B. \& Daniels, K., 2013, A day in the life of a happy worker, Psychology Press, New York.

Belkin, L., 2007, 'When whippersnappers and geezers collide', The New York Times, July 26, viewed 18 May, 2018, from https://www.nytimes.com/2007/07/26/ fashion/26work.html.

Binnewies, C., Sonnentag, S. \& Mojza, E.J., 2010, 'Recovery during the weekend and fluctuations in weekly job performance: A week-level study examining intraindividual relationships', Journal of Occupational \& Organizational Psychology 83(2), 419-441. https://doi.org/10.1348/096317909X418049 
Bolton, S.C. \& Plester, B., 2009, 'Crossing the line: Boundaries of workplace humour and fun', Employee Relations 31(6), 584-599. https://doi.org/10.1108/014254509 10991749

Boot, W.R., Simons, D.J., Stothart, C. \& Stutts, C., 2013, 'The pervasive problem with placebos in psychology: Why active control groups are not sufficient to rule out placebo effects', Perspectives on Psychological Science 8(4), 445-454. https://doi. org/10.1177/1745691613491271

Butler, N., Olaison, L., Sliwa, M., Sørensen, B.M. \& Spoelstra, S., 2011, 'Work, play and boredom', Ephemera Theory \& Politics in Organization 11(4), 329-335.

Cummings, M.L., Gao, F. \& Thornburg, K.M., 2016, 'Boredom in the workplace: A new look at an old problem', Human Factors 58(2), 279-300. https://doi.org/ 10.1177/0018720815609503

Demerouti, E., Bakker, A.B., Sonnentag, S. \& Fullagar, C.J., 2012, 'Work-related flow and energy at work and at home: A study on the role of daily recovery', Journal of Organizational Behavior 33(2), 276-295. https://doi.org/10.1002/job.760

Elliott, A.C. \& Woodward, W.A., 2007, Statistical analysis quick reference guidebook: With SPSS examples, Sage, Thousand Oaks, CA.

Ellis, P.D., 2010, The essential guide to effect sizes: Statistical power, meta-analysis, and the interpretation of research results, Cambridge University Press, Cambridge.

Engeser, S. \& Rheinberg, F., 2008, 'Flow, performance and moderators of challengeskill balance', Motivation and Emotion 32(3), 158-172. https://doi.org/10.1007/ s11031-008-9102-4

Feuerhahn, N., Sonnentag, S. \& Woll, A., 2014, 'Exercise after work, psychological mediators, and affect: A day-level study', European Journal of Work \& Organizationa Psychology 23(1), 62-79. https://doi.org/10.1080/1359432X.2012.709965

Fluegge-Woolf, E., 2014, 'Play hard, work hard: Fun at work and job performance', Management Research Review 37(8), 682-705. https://doi.org/10.1108/MRR-112012-0252

Fredrickson, B.L. Cohn, M.A. Coffey, K.A., Pek, J. \& Finkel, S.M., 2008, 'Open hearts build lives: Positive emotions, induced through loving-kindness meditation, build consequential personal resources', Journal of Personality and Social Psychology 95(5), 1045-1062. https://doi.org/10.1037/a0013262

Graves, L.M., Ruderman, M.N., Ohlott, P.J. \& Weber, T.J., 2012, 'Driven to work and enjoyment of work: Effects on managers' outcomes', Journal of Management enjoyment of work: Effects on managers' outcomes', Journal
38(5), 1655-1680. https://doi.org/10.1177/0149206310363612

Hahn, V.C., Binnewies, C. \& Haun, S., 2012, 'The role of partners for employees' recovery during the weekend', Journal of Vocational Behavior 80, 288-298. https://doi.org/10.1016/j.jvb.2011.12.004

Halbesleben, J.R.B., Wheeler, A.R. \& Paustian-Underdahl, S.C., 2013, 'The impact of furloughs on emotional exhaustion, self-rated performance, and recovery experiences', Journal of Applied Psychology 98(3), 492-503. https://doi.org/10.1037/ a0032242

Han, H., Kim, W. \& Jeong, C., 2016, 'Workplace fun for better team performance: Focus on frontline hotel employees', International Journal of Contemporary Hospitality Management 28(7), 1391-1416. https://doi.org/10.1108/IJCHM-112014-0555

Hsiao, J.P.H., Jaw, C., Huan, T.C. \& Woodside, A.G., 2015, 'Applying complexity theory to solve hospitality contrarian case conundrums: Illuminating happy-low and unhappy-high performing frontline service employees', International Journal of Contemporary Hospitality Management 27(4), 608-647. https://doi.org/10.1108/ IJCHM-11-2013-0533

Hülsheger, U.R., 2016, 'From dawn till dusk: Shedding light on the recovery process by investigating daily change patterns in fatigue', Journal of Applied Psychology 101(6), 905-914. https://doi.org/10.1037/apl0000104

IBM Corp., 2017, IBM SPSS statistics for windows, version 24.0, IBM Corp., Armonk, NY. Jackson, N. \& Carter, P., 2011, 'In praise of boredom', Ephemera: Theory \& Politics in Organization 11(4), 387-405.

Kapp, K.M., 2012, The gamification of learning and instruction, Wiley, San Francisco.

Karl, K.A., Peluchette, J.V. \& Harland, L., 2007, 'Is fun for everyone? Personality differences in healthcare providers' attitudes toward fun', Journal of Health and Human Services Administration 29(4), 409-447.

Kasper-Brauer, K. \& Leischnig, A., 2016, 'Yes, we can! A fuzzy-set analysis of challenges, skills, and enjoyment of work', Journal of Business Research 69(11), 5286-5291. https://doi.org/10.1016/j.jbusres.2016.04.126

Kompier, M.A.J., Taris, T.W. \& Van Veldhoven, M., 2012, 'Tossing and turning Insomnia in relation to occupational stress, rumination, fatigue, and well-being', Scandinavian Journal of Work, Environment \& Health 38(3), 238-246. https://doi. org/10.5271/sjweh.3263

Loukidou, L., Loan-Clarke, J. \& Daniels, K., 2009, 'Boredom in the workplace: More than monotonous tasks', International Journal of Management Reviews 11(4), 381-405. https://doi.org/10.1111/j.1468-2370.2009.00267.x

Maiga, A.S., Nilsson, A. \& Ax, C., 2015, 'Relationships between internal and external information systems integration, cost and quality performance, and firm profitability', International Journal of Production Economics 169, 422-434. http:// doi.org/10.1016/j.ijpe.2015.08.030

Moreno-Jiménez, B., Rodríguez-Muñoz, A., Pastor, J.C., Sanz-Vergel, A.I. \& Garrosa, E. 2009 , 'The moderating effects of psychological detachment and thoughts of revenge in workplace bullying', Personality and Individual Differences 46(3), 359364. https://doi.org/10.1016/j.paid.2008.10.031

Moreno-Jiménez, B., Rodríguez-Muñoz, A., Sanz-Vergel, A.I. \& Garrosa, E., 2012, 'Elucidating the role of recovery experiences in the job demands-resources model', The Spanish Journal of Psychology 15(2), 659-669. http://doi.org/ 10.5209/rev_SJOP.2012.v15.n2.38877
Oerlemans, W.G.M., Bakker, A.B. \& Demerouti, E., 2014, 'How feeling happy during off-job activities helps successful recovery from work: A day reconstruction study',
Work \& Stress 28(2), 198-216. https://doi.org/10.1080/02678373.2014.901993

Perryer, C., Celestine, N.A., Scott-Ladd, B. \& Leighton, C., 2016, 'Enhancing workplace motivation through gamification: Transferable lessons from pedagogy', The International Journal of Management Education 14(3), 327-335. https://doi. org/10.1016/j.jime.2016.07.001

Peters, P., Poutsma, E., Van der Heijden, B.I.J.M., Bakker, A.B. \& De Bruijn, T., 2014, 'Enjoying new ways to work: An HRM-process approach to study flow', Human Resource Management 53(2), 271-290. https://doi.org/10.1002/hrm.21588

Reid, H.M., 2013, Introduction to statistics: Fundamental concepts and procedures of data analysis, Sage, Thousand Oaks, CA.

Reijseger, G., Schaufeli, W.B., Peeters, M.C.W., Taris, T.W., Van Beek, I. \& Ouweneel, E., 2013, 'Watching the paint dry at work: Psychometric examination of the Dutch Boredom Scale', Anxiety, Stress \& Coping 26(5), 508-525. https://doi.org/10.1080 /10615806.2012.720676

Rodríguez-Muñoz, A. \& Sanz-Vergel, A.l., 2013, 'Happiness and well-being at work: A special issue introduction', Revista de Psicología Del Trabajo Y de Las Organizaciones 29(3), 95-97. https://doi.org/10.5093/tr2013a14

Romero, E. \& Pescosolido, A., 2008, 'Humor and group effectiveness', Human Relations 61(3), 395-418. https://doi.org/10.1177/0018726708088999

Rotundo, M. \& Sackett, P.R., 2002, 'The relative importance of task, citizenship, and counterproductive performance to global ratings of job performance: A policycapturing approach', Journal of Applied Psychology 87(1), 66-80. https://doi. org/10.1037//0021-9010.87.1.66

Sanz-Vergel, A.I. \& Muñoz, A.R., 2013, 'The spillover and crossover of daily work enjoyment and well-being: A diary study among working couples', Revista de Psicología Del Trabajo Y de Las Organizaciones 29(3), 179-185. https://doi. org/10.5093/tr2013a24

Schaufeli, W.B. \& Salanova, M., 2014, 'Burnout, boredom and engagement in the workplace', in M.C.W. Peeters, J. De Jonge \& T.W. Taris (eds.), An introduction to contemporary work psychology, pp. 293-320, Wiley-Blackwell, West Sussex.

Schönbrodt, F.D. \& Perugini, M., 2013, 'At what sample size do correlations stabilize?', Journal of Research in Personality 47(5), 609-612. https://doi.org/10.1016/j. jrp.2013.05.009

Sonnentag, S., Binnewies, C. \& Mojza, E.J., 2010, 'Staying well and engaged when demands are high: The role of psychological detachment', Journal of Applied Psychology 95(5), 965-976. https://doi.org/10.1037/a0020032

Sonnentag, S. \& Fritz, C., 2007, 'The Recovery Experience Questionnaire: Development and validation of a measure for assessing recuperation and unwinding from work', Journal of Occupational Health Psychology 12(3), 204-221. https://doi. org/10.1037/1076-8998.12.3.204

Sonnentag, S. \& Fritz, C., 2015, 'Recovery from job stress: The stressor-detachment model as an integrative framework', Journal of Organizational Behaviour 36(Suppl. 1), 72-103. https://doi.org/10.1002/job.1924

Sonnentag, S. \& Kühnel, J., 2016, 'Coming back to work in the morning: Psychological detachment and reattachment as predictors of work engagement', Journal of Occupational Health Psychology 21(4), 379-390. https://doi.org/10.1037/ocp0000020

Sonnentag, S., Unger, D. \& Nägel, I.J., 2013, 'Workplace conflict and employee wellbeing: The moderating role of detachment from work during off-job time', International Journal of Conflict Management 24(2), 166-183. https://doi. org/10.1108/10444061311316780

Sørensen, B.M. \& Spoelstra, S., 2012, ‘Play at work: Continuation, intervention and usurpation',Organization19(1),81-97.https://doi.org/10.1177/1350508411407369

Spraggon, M. \& Bodolica, V., 2014, 'Social ludic activities: A polymorphous form of organizational play', Journal of Managerial Psychology 29(5), 524-540. https:// doi.org/10.1108/JMP-01-2012-0009

Struwig, F.W. \& Stead, G.B., 2013, Planning, designing and reporting research, 9th edn., Pearson Education South Africa, Cape Town.

Sukovic, S., Litting, D. \& England, A., 2011, 'Playing with the future: Library engagement and change', Australian Academic \& Research Libraries 42(2), 70-87. https://doi org/10.1080/00048623.2011.10722215

Tews, M.J., Michel, J.W. \& Bartlett, A., 2012, 'The fundamental role of workplace fun in applicant attraction', Journal of Leadership \& Organizational Studies 19(1), 105-114. https://doi.org/10.1177/1548051811431828

Tews, M.J., Michel, J.W. \& Noe, R.A., 2017, 'Does fun promote learning? The relationship between fun in the workplace and informal learning', Journal of Vocational Behavior 98, 46-55. https://doi.org/10.1016/j.jvb.2016.09.006

Tews, M.J., Michel, J.W. \& Stafford, K., 2013, 'Does fun pay? The impact of workplace fun on employee turnover and performance', Cornell Hospitality Quarterly 54(4), 370-382. https://doi.org/10.1177/1938965513505355

Trougakos, J.P. \& Hideg, I., 2009, 'Momentary work recovery: The role of within-day work breaks', in P. Perrewé, J. Halbesleben \& C. Rose (eds.). Current perspectives on job-stress recovery, vol. 7, pp. 37-84, Emerald Group Publishing Limited, Bingley.

Tucker, P., Dahlgren, A., Akerstedt, T. \& Waterhouse, J., 2008, 'The impact of free-time activities on sleep, recovery and well-being', Applied Ergonomics 39(5), 653-662. https://doi.org/10.1016/j.apergo.2007.12.002

Van Veldhoven, M., Meijman, T.F., Broersen, J.P.J. \& Fortuin, R.J., 1997, Handleiding VBBA: Onderzoek naar de beleving van psychosociale arbeidsbelasting en werkstress met behulp van de vragenlijst beleving en beoordeling van de arbeid [Manual VBBA: Research on the experience of psychosocial workload and job [Manual VBBA: Research on the experience of psychosocial workload and job sKB, Amsterdam. 
Van Wyk, S.M., De Beer, L.T., Pienaar, J. \& Schaufeli, W.B., 2016, 'The psychometric properties of a workplace boredom scale (DUBS) within the South African context', SA Journal of Industrial Psychology 42(1), 1-10. https://doi.org/10.4102/ sajip.v42i1.1326

Verenikina, I. \& Hasan, H.M., 2010, 'The importance of play in organisation', in H. Yeatman (eds.), The SInet 2010 eBook, pp. 120-134, SInet UOW, Wollongong.

Volman, F.E., Bakker, A.B. \& Xanthopoulou, D., 2013, 'Recovery at home and performance at work: A diary study on self-family facilitation', European Journa of Work and Organizational Psychology 22(2), 218-234. https://doi.org/10.1080/ $1359432 X .2011 .648375$
West, S., 2015, 'Playing at work: Organizational play as a facilitator of creativity', Doctoral thesis, Lund University, Sweden. Available from http://eds.b.ebscohost. com.nwulib.nwu.ac.za/.

Xanthopoulou, D., Bakker, A.B. \& Ilies, R., 2012, 'Everyday working life: Explaining within-person fluctuations in employee well-being', Human Relations 65(9), 1051-1069. https://doi.org/10.1177/0018726712451283

Zijlstra, F.R.H., Cropley, M. \& Rydstedt, L.W., 2014, 'From recovery to regulation: An attempt to reconceptualise "recovery from work"', Stress \& Health: Journal of the International Society for the Investigation of Stress 30(3), 244-252. https://doi. org/10.1002/smi.2604 